\title{
Quantification of total carbon in soil using laser-induced breakdown spectroscopy: a method to correct interference lines
}

\author{
Gustavo Nicolodelli, ${ }^{1}$ Bruno S. Marangoni, ${ }^{1,2}$ Jader S. Cabral, ${ }^{1,3}$ Paulino R. Villas-Boas, ${ }^{1}$ \\ Giorgio S. Senesi, ${ }^{4}$ Cléber Hilario dos Santos, ${ }^{1,5}$ Renan A. Romano, ${ }^{1,6}$ Aline Segnini, ${ }^{1}$ \\ Yves Lucas, ${ }^{7}$ Célia R. Montes, ${ }^{8}$ and Débora M. B. P. Milori ${ }^{1, *}$ \\ ${ }^{1}$ Embrapa Instrumentação, P.O. Box 741, 13560-970 São Carlos, SP, Brazil \\ ${ }^{2}$ Departamento de Física, Universidade Federal de São Carlos, P.O. Box 676, 13565-905 São Carlos, SP, Brazil \\ ${ }^{3}$ Instituto de Física, Universidade Federal de Uberlândia, P.O. Box 593, 38400-902 Uberlândia, MG, Brazil \\ ${ }^{4}$ Institute of Inorganic Methodologies and Plasmas-CNR-Bari, 70126 Bari, Italy \\ ${ }^{5}$ Instituto de Química de São Carlos, Universidade de São Paulo, P.O. Box 780, 13560-970 São Carlos, SP, Brazil \\ ${ }^{6}$ Instituto de Física de São Carlos, Universidade de São Paulo, P.O. Box 369, 13560-970 São Carlos, SP, Brazil \\ ${ }^{7}$ Université de Toulon, PROTEE, EA 3819, 83957 La Garde, France \\ ${ }^{8}$ NUPEGEL, Centro de Energia Nuclear na Agricultura, Universidade de São Paulo, \\ P.O. Box 09, 13418-900 Piracicaba, SP, Brazil \\ *Corresponding author: debora.milori@embrapa.br
}

Received 18 December 2013; revised 14 February 2014; accepted 14 February 2014; posted 21 February 2014 (Doc. ID 203229); published 31 March 2014

\begin{abstract}
The $\mathrm{C}$ cycle in the Brazilian forests is very important, mainly for issues addressed to climate changes and soil management. Assessing and understanding $\mathrm{C}$ dynamics in Amazonian soils can help scientists to improve models and anticipate scenarios. New methods that allow soil C measurements in situ are a crucial approach for this kind of region, due to the costs for collecting and sending soil samples from the rainforest to the laboratory. Laser-induced breakdown spectroscopy (LIBS) is a multielemental atomic emission spectroscopy technique that employs a highly energetic laser pulse for plasma production and requires neither sample preparation nor the use of reagents. As LIBS takes less than 10 s per sample measurement, it is considered a promising technique for in situ soil analyses. One of the limitations of portable LIBS systems, however, is the common overlap of the emission lines that cannot be spectrally resolved. In this study a method was developed capable of separating the $\mathrm{Al}$ interference from the $\mathrm{C}$ emission line in LIBS measurements. Two typical forest Brazilian soils rich in $\mathrm{Al}$ were investigated: a spodosol (Amazon Forest) and an oxisol (Atlantic Forest). Fifty-three samples were collected and analyzed using a low-resolution LIBS apparatus to measure the intensities of C lines. In particular, two C lines were evaluated, at 193.03 and $247.86 \mathrm{~nm}$. The line at $247.86 \mathrm{~nm}$ showed very strong interference with $\mathrm{Fe}$ and $\mathrm{Si}$ lines, which made quantitative analysis difficult. The line at $193.03 \mathrm{~nm}$ showed interference with atomic and ionic $\mathrm{Al}$ emission lines, but this problem could be solved by applying a correction method that was proposed and tested in this work. The line at 247.86 was used to assess the proposed model. The strong correlation (Pearson's coefficient $R=0.91$ ) found between the LIBS values and those obtained by a reference technique (dry combustion by an elemental analyzer) supported the validity of the proposed method. () 2014 Optical Society of America
\end{abstract}

OCIS codes: (140.3440) Laser-induced breakdown; (300.6210) Spectroscopy, atomic; (300.6365) Spectroscopy, laser induced breakdown.

http://dx.doi.org/10.1364/AO.53.002170

$1559-128 \mathrm{X} / 14 / 102170-07 \$ 15.00 / 0$

(C) 2014 Optical Society of America 


\section{Introduction}

Forests play a fundamental role in the cycle of $\mathrm{C}$ due to their high phytomass and sensitivities to anthropogenic pressure [1,2]. Forests are important environmental service providers of biodiversity, C sequestration, regulation of water resources, and nutrient cycles. Most of these services help to sustain the local, regional, and global human life [3, $\underline{4}]$.

The Amazon rainforest is a huge and dynamic reservoir of C, but this $\mathrm{C}$ can be released to the atmosphere due to deforestation, nonconservative land use, and climate change [5-7]. In the Amazon, relationships between soil $\mathrm{C}$ stocks and $\mathrm{C}$ sequestration in natural vegetation are poorly understood. Moreover, the permanence of $\mathrm{C}$ in the forest soil as well as the quantity of organic $\mathrm{C}$ resources is highly influenced by the soil type and associated vegetation. The Amazon has a wide area of spodosols characterized by thick sandy horizons overlying clayey horizons often associated with oxisols in oxisols-spodosols systems $[7,8]$.

Recently, research efforts have focused on measuring soil $\mathrm{C}$ in situ using a variety of methods. These methods include inelastic neutron scattering (INS), near-infrared spectroscopy (NIRS), and other techniques [9-12]. The technique most commonly used for $\mathrm{C}$ determination in soil is dry combustion by an elemental analyzer, as recommended by the Intergovernmental Panel on Climate Changes for soil $\mathrm{C}$ stock evaluation $[1,6]$. To determine the concentration of other elements, absorption or emission atomic spectroscopy techniques are commonly used. Therefore, the determination of $\mathrm{C}$ and other elements in soil samples demands at least two analytical techniques and requires several supplies that increase analytical costs.

Laser-induced breakdown spectroscopy (LIBS) is an analytical technique based on the atomic and ionic emissions from elemental constituents of the sample [13,14]. LIBS is able to perform direct and simultaneous multielemental analysis without any sample pretreatment or use of reagents, and shows promising potential to perform in situ analysis [13]. This technique is based on the spectral analysis of the radiation emitted by the plasma generated by focusing an intense laser pulse on the sample surface, which causes evaporation, atomization, and ionization emitting radiations characteristic of the elements present in the material under study. A qualitative analysis of the LIBS emission spectrum provides a fingerprint of the sample with respect to its elemental composition [14]. LIBS has been successfully employed for qualitative and quantitative analysis of samples of very diverse nature and origin, including soils, to determine the content of $\mathrm{C}$, various elements, and pollutants [15-26]. Also, a number of techniques, such as dual-pulse excitation, have been used to improve the sensitivity [18] and spectral resolution [27] of LIBS.

Over the years, LIBS measurements of total $\mathrm{C}$ content in soils have been systematically improved by several research teams [15-18,20,25,26]. Most studies concerning atomic $\mathrm{C}$ emission have considered two lines of $\mathrm{C}$ at 193.03 and at $247.8 \mathrm{~nm}$ [15$\underline{18}, 20, \underline{25}, \underline{26]}$.

This study aimed to develop a method to quantify $\mathrm{C}$ in Brazilian soils using atomic emission lines obtained by a portable LIBS system. This system, however, suffers from some disadvantages, particularly poor sensitivity and low resolution [full-width at half-maximum (FWHM) is $>0.1 \mathrm{~nm}]$. As a consequence, the $\mathrm{C}$ lines at 193.03 and $247.86 \mathrm{~nm}$ are strongly interfered by $\mathrm{Al}$ and $\mathrm{Fe}$ emission lines, respectively. In particular, forest Brazilian soils are very rich in $\mathrm{Fe}$ and/or $\mathrm{Al}$ that determine a strong interference problem for the measurement of C. For this reason we have proposed and investigated a novel analytical method to quantify $\mathrm{C}$ in spodosols and oxisols, which is able to correct for the interference of $\mathrm{Al}$ lines with the $\mathrm{C}$ line at $193.03 \mathrm{~nm}$.

\section{Materials and Methods}

The soil samples were collected from two Brazilian forests, a spodosol and an oxisol. The spodosol samples were collected from the dense Amazonian rainforest close to the city of São Gabriel da Cachoeira, Amazon State. It comprises the following vertical sequence of horizons: A1 and A2 (organic-mineral surface), E1 and E2 (albics), Bh and Bhs (spodics), Tr (transition layer), and K1 and K2 (layers of bleached kaolin) at the bottom (Table 1). One sample of each horizon was sampled along a deep profile. Red oxisol samples were collected from a remnant of the Atlantic Forest close to the city of Sao Carlos, Sao Paulo State, at eight depths ranging from 0 to $1 \mathrm{~m}$ (Table 1). The $\mathrm{C}, \mathrm{Al}$, and $\mathrm{Fe}$ contents of soil samples are shown in Table $\underline{1}$.

Table 1. Characteristics of the Soil Samples Examined

\begin{tabular}{lcccc}
\hline & $\begin{array}{c}\text { Depth } \\
(\mathrm{cm})\end{array}$ & $\% \mathrm{C}$ & $\begin{array}{c}\% \mathrm{Al} \\
\left(\times 10^{-4}\right)\end{array}$ & $\begin{array}{c}\% \mathrm{Fe} \\
\left(\times 10^{-4}\right)\end{array}$ \\
\hline Horizon & & & & \\
A1 & $0-5$ & $2.97 \pm 0.01$ & 24.96 & 3.55 \\
A2 & $5-30$ & $0.76 \pm 0.01$ & 10.75 & 1.76 \\
E1 & $30-180$ & $<\mathrm{LOD}^{a}$ & 0.95 & 0.39 \\
E2 & $180-202$ & $<\mathrm{LOD}^{a}$ & 2.43 & 0.91 \\
Bh & $202-204$ & $0.30 \pm 0.07$ & 35.98 & 5.13 \\
Bhs & $204-214$ & $0.36 \pm 0.06$ & 59.92 & 8.95 \\
Tr & $214-245$ & $3.21 \pm 0.01$ & 610.15 & 1.31 \\
K1 & $245-290$ & $0.69 \pm 0.07$ & 326.44 & 34.77 \\
K2 & $290+$ & $<\mathrm{LOD}^{a}$ & 273.26 & 3.14 \\
Oxisol & & & & \\
Oxi1 & $0-5$ & $2.37 \pm 0.53$ & $<\mathrm{LOD}^{a}$ & 24 \\
Oxi2 & $5-10$ & $1.78 \pm 0.31$ & 6.5 & 22.17 \\
Oxi3 & $10-20$ & $1.29 \pm 0.09$ & 4.3 & 20.7 \\
Oxi4 & $20-30$ & $1.06 \pm 0.09$ & 19.5 & 19.2 \\
Oxi5 & $30-40$ & $0.92 \pm 0.03$ & 36.8 & 16.8 \\
Oxi6 & $40-60$ & $0.82 \pm 0.03$ & 28.2 & 14 \\
Oxi7 & $60-80$ & $0.74 \pm 0.09$ & 21.7 & 12.3 \\
Oxi8 & $80-100$ & $0.67 \pm 0.18$ & 10.8 & 10.5 \\
\hline
\end{tabular}

${ }^{a}$ Lower than the limit of detection (LOD) of the reference techniques. 
The soil samples were sieved to remove roots, and grinded to obtain particles smaller than $0.15 \mathrm{~mm}$. Pellets of the homogenized samples were prepared using a press of 5 tons for $30 \mathrm{~s}$. Aluminum alloy blade $(99.50 \% \mathrm{Al})$ and pellets prepared with a graphite (3\%)/boric acid (97\%) mixture were used as reference samples.

The measurements were performed using a LIBS2500 spectrometer (Ocean Optics, Dunedin, USA), equipped with a $Q$-switched $1064 \mathrm{~nm} \mathrm{Nd:}$ YAG laser manufactured by Quantel (Big Sky Laser Ultra50) and operating at a $75 \mathrm{~mJ}$ maximum power energy and a $10 \mathrm{~Hz}$ frame rate. The laser beam was focused over the sample inside an ablation chamber. Plasma emission was collected by an optical fiber bundle connected to seven spectrometers, each one providing a 2048 element linear silicon CCD array. All tests were carried out in air. The distance from the sample to the collecting optical fiber bundle was approximately $7 \mathrm{~mm}$. The spectra were acquired from 189 to $966 \mathrm{~nm}$ with an approximate optical resolution of $0.1 \mathrm{~nm}$. On each soil sample, 60 measurements were performed, each one corresponding to two accumulated shots. The LIBS equipment was settled to an $8 \mathrm{~ns}, 50 \mathrm{~mJ}$ pulse with a $2.1 \mathrm{~ms}$ integration time for all measurements. The offset of the LIBS spectra was corrected by subtracting the average of the random noise region close to the $\mathrm{C}$ element emission line. After the offset correction, the relation signal/noise was improved by averaging 60 spectra. In order to remove the outlier spectra, we applied a mathematical method named spectral angle mapper (SAM). This algorithm compares two spectra and returns a scalar value based on its similarity. Imposing a maximum limit to this number, we can exclude spectra that do not show similar behavior to the rest of them.

An inductively coupled plasma optical emission spectrometer (ICP OES) with a radially viewed configuration, model VISTA PROCCD (Varian), was used for $\mathrm{Fe}$ and $\mathrm{Al}$ reference determinations. Before ICP OES measurements, a digestion step was performed in an open system at a temperature of $110^{\circ}$ $\mathrm{C}-120^{\circ} \mathrm{C}$ using $1 \mathrm{~g}$ of soil sample and $20 \mathrm{ml}$ of aqua regia (1HNO3: $3 \mathrm{HC}$ ).

The total $\mathrm{C}$ content of soil samples was measured by a Perkin-Elmer $2400 \mathrm{CHNS/O}$ analyzer series II. Soil samples were grinded into particles smaller than $0.15 \mathrm{~mm}$, and then weighed directly in consumable tin capsules using a microbalance (PerkinElmer AD-6 Auto Balance Controller) that was connected to the $2400 \mathrm{CHNS} / \mathrm{O}$ for direct mass acquisition. The tin capsules were then closed and inserted inside the furnace. All results of elemental analysis were calculated with reference to the known $\mathrm{C}$ value of acetanilide, an organic standard of known elemental composition, by using the $\mathrm{K}$ value factor calculation.

\section{Results and Discussion}

Figure 1 shows the typical LIBS spectra of samples from the transition layer of a spodosol from the
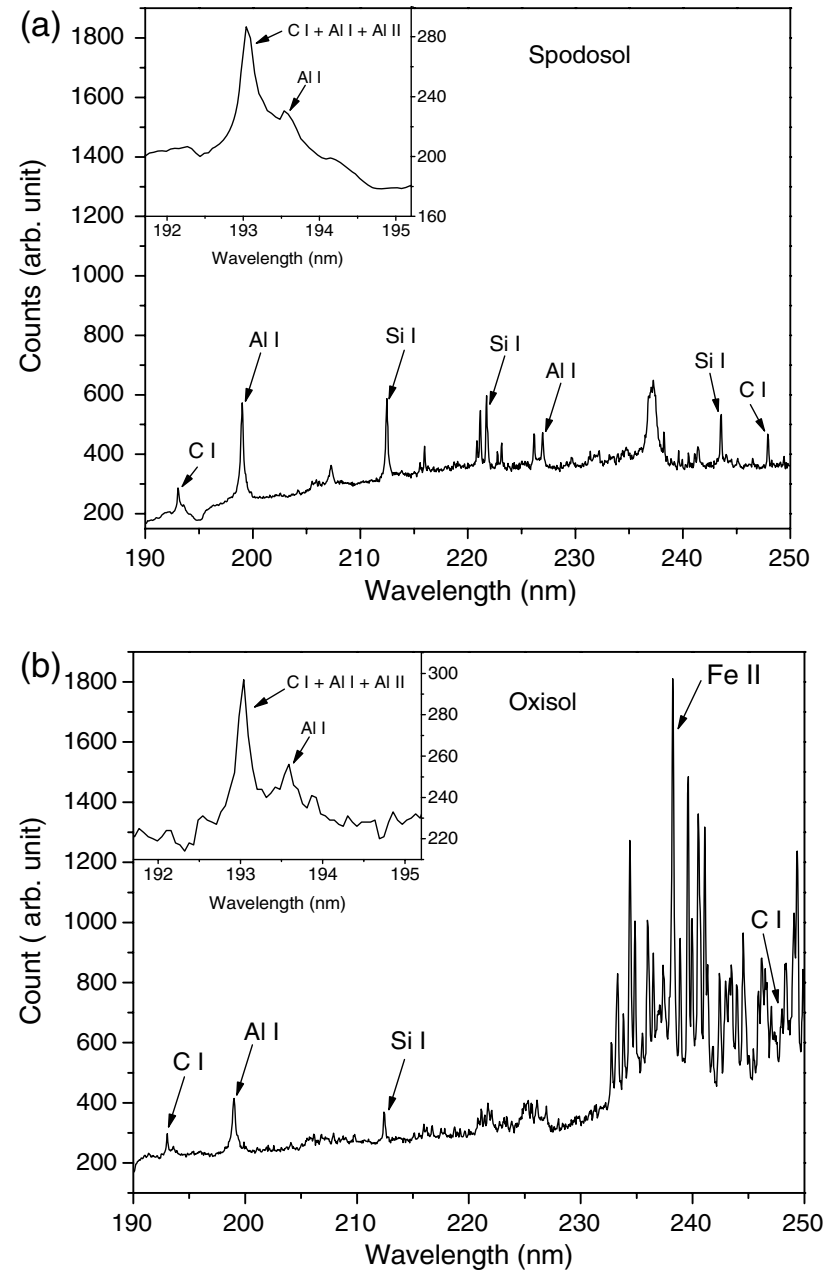

Fig. 1. LIBS spectra of (a) spodosol and (b) oxisol samples.

Amazon Forest (Tr) [Fig. 1(a)] and an oxisol from the Atlantic Forest [Fig. 1(b)].

According to the NIST database, the most intense atomic C lines between 189 and $966 \mathrm{~nm}$, i.e., at $193.03 \mathrm{~nm}$ (relative intensity 1000 and Einstein coefficient $3.4 \times 10^{8} \mathrm{~s}^{-1}$ ) and at $247.86 \mathrm{~nm}$ (relative intensity 800 and Einstein coefficient $2.8 \times 10^{7} \mathrm{~s}^{-1}$ ), were detected by our experimental apparatus for all soil samples examined. To ensure the correct $\mathrm{C}$ peak position, a LIBS measurement was also performed on the pellet of graphite.

In the LIBS spectrum of spodosol samples [Fig. 1(a)], no Fe lines are detected possibly because the concentration of $\mathrm{Fe}$ in these soils is below the LIBS limit of detection. However, it is important to emphasize that Brazilian soils $[7,8,17]$ are generally very rich in $\mathrm{Fe}$, which prevents $\mathrm{C}$ quantification using the $\mathrm{C}$ line at $247.86 \mathrm{~nm}$ without a proper correction to eliminate or reduce $\mathrm{Fe}$ interference. In the LIBS spectrum of oxisol samples [Fig. 1(b)], the C line at $247.86 \mathrm{~nm}$ clearly suffers the interference of several $\mathrm{Fe}, \mathrm{Ti}$, and $\mathrm{Si}$ emission lines, mainly the Fe line at $247.94 \mathrm{~nm}$. However, several studies considered the C line at $247.86 \mathrm{~nm}$ as most spectrometers have the minimal spectral limit of detection at 


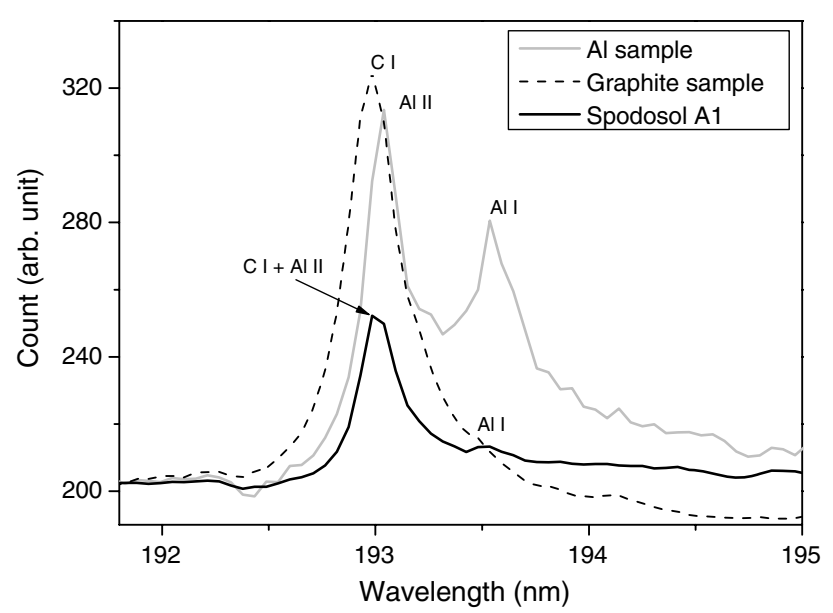

Fig. 2. LIBS spectra of the Oxi1 layer (solid line) of the oxisol sample, an $\mathrm{Al}$ alloy blade sample (gray line), and a graphite sample (dashed line). The $\mathrm{C}$ line at $193.03 \mathrm{~nm}$ and the $\mathrm{Al}$ lines at 193.04 and $193.58 \mathrm{~nm}$ are indicated.

$200 \mathrm{~nm}[15,18,25,26]$, and data treatment is complex in this case, mainly due to the lack of a clear baseline (the profile is mixed with the background radiation).

The C line at $193.03 \mathrm{~nm}$ in both soil samples is interfered by three Al lines: 193.04 (ionic), 193.16 (atomic), and 193.58 (atomic) $\mathrm{nm}$, and cannot be spectrally resolved in this LIBS systems [Fig. 1(a)]. Figure 2 shows the emission spectrum of the Oxi1 layer of the red oxisol sample (solid line) compared to the $\mathrm{Al}$ alloy blade $\mathrm{Al}$ (gray line) and to the graphite pellet (dashed line).

According to Fig. 1(a), the spodosol spectrum lacks $\mathrm{Fe}$ lines close the $\overline{\mathrm{C}}$ line at $247.86 \mathrm{~nm}$; thus these samples were used to test the model proposed below. The Al I line (193.58 nm) was used to correct the interference of $\mathrm{Al}$ II transition (193.04 $\mathrm{nm}$ ) with the C I line $(193.03 \mathrm{~nm})$ peak. Due to the low resolution of the spectrometer, a double function fit was necessary. The Gaussian function was chosen because of the small error in the fitting process. Area $1\left(A_{C+\mathrm{Al}}\right)$, corresponding to the transitions at $193.03 \mathrm{~nm}$ $(C I+\mathrm{Al} I I+\mathrm{Al} I)$, and Area $2\left(A_{\mathrm{Al}}\right)$ at $193.58 \mathrm{~nm}$ (Al I) were extrapolated after performing a double Gaussian fit in the spectral range. The areas were plotted according to Eq. (1):

$$
A_{C+\mathrm{Al}}-\alpha_{1} A_{\mathrm{Al}}=A_{C 247},
$$

where $A_{C 247}$ corresponds to a pure $\mathrm{C}$ peak at $247.86 \mathrm{~nm}$. The " $\alpha$ " parameter was optimized by performing a linear fitting for the best Pearson's coefficient. Assuming the proportionality between the $\mathrm{Al}$ lines (193.04 and $193.58 \mathrm{~nm}$ ), this optimized parameter can correct the $\mathrm{Al}$ interference with the 193.03 nm C line.

In order to apply Eq. (1), two assumptions are necessary: (a) the excitation temperature has to be the same for all samples and (b) the ratio between the intensities of the atomic and ionic $\mathrm{Al}$ line have to be constant for all spectra. The first assumption

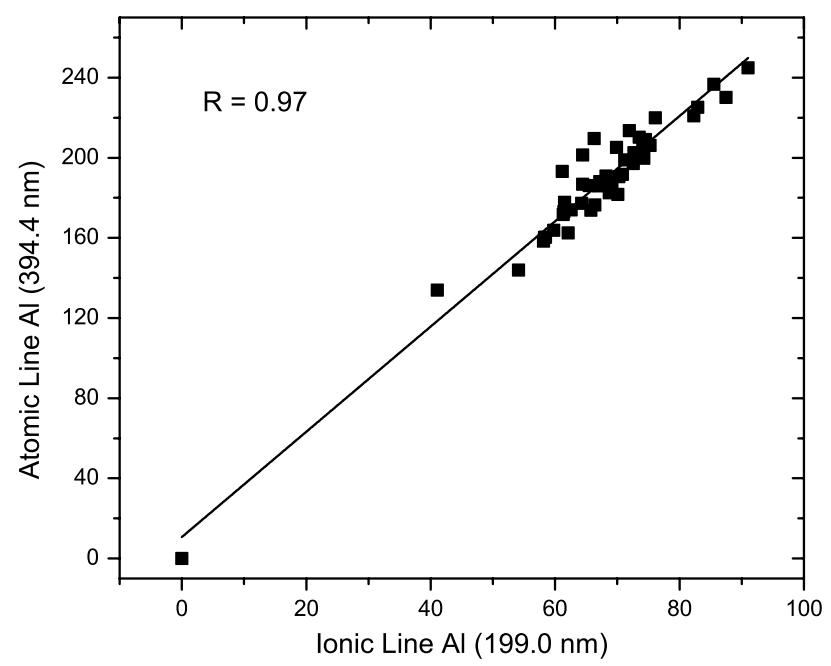

Fig. 3. Linear correlation between the intensity of the ionic $\mathrm{Al}$ line at $394.4 \mathrm{~nm}$ and the intensity of the atomic $\mathrm{Al}$ line at $199.0 \mathrm{~nm}$. The Pearson's coefficient was 0.97.

was satisfied, because the excitation temperature obtained by the Ti Boltzmann plot had the value of $9200 \pm 2100 \mathrm{~K}$ for all analyzed samples. The electron density value of $2.6 \pm 0.610^{18} \mathrm{~cm}^{-3}$ was also estimated by the two $\mathrm{Ti}$ lines, at 394.78 (atomic) and 439.50 (ionic). The second assumption was also satisfied as a linear correlation was found between the intensity of the $\mathrm{Al}$ ionic line at $394.4 \mathrm{~nm}$ and the intensity of the $\mathrm{Al}$ atomic line at $199.0 \mathrm{~nm}$, as shown in Fig. 3. The Pearson's coefficient $(R)$ was higher than $0.9 \overline{7}$, and the fitting error was about $6 \%$. Thus, the high correlation between atomic and ionic $\mathrm{Al}$ lines allows extracting the interference of the ionic $\mathrm{Al}$ line from the $\mathrm{C}$ line at $193.03 \mathrm{~nm}$ through the atomic $\mathrm{Al}$ line at $193.58 \mathrm{~nm}$ using Eq. (1).

Figure $\underline{4}$ shows the differences between the LIBS intensities of the $\mathrm{C}$ line at $193.03 \mathrm{~nm}$ without [Fig. 4(a)] and with [Fig. 4(b)] the correction by the $\mathrm{Al}$ line, as a function of the $\mathrm{C}$ line at $247.86 \mathrm{~nm}$. In Fig. 4(b), the value of the parameter $\alpha$ in Eq. (1) has the best fit of $1.20 \pm 0.05$. The Pearson's correlation coefficients obtained without and with the $\mathrm{Al}$ correction were, respectively, 0.86 and 0.96. Further, in this case, there was no interference by $\mathrm{Fe}$ and $\mathrm{Ti}$ on the $247.86 \mathrm{C}$ line.

Thus, the linear model tested to remove the interference of $\mathrm{Al}$ with the $\mathrm{C}$ line at $193.03 \mathrm{~nm}$ using the $\mathrm{C}$ line at $247.86 \mathrm{~nm}$ as reference data was successful. However, by correlating the LIBS data (C line at 193.03 corrected by the $\mathrm{Al}$ line and the $\mathrm{C}$ line at 247.86) and elemental analysis data a nonlinear correlation was found, possibly due to self-absorption of the investigated lines. Thus, a logarithmic model [Eq. (2)] is proposed to correct the $\mathrm{Al}$ interference with the $\mathrm{C}$ line, which can efficiently fit LIBS data with CHN analysis data:

$$
A_{C+\mathrm{Al}}-\alpha_{2} A_{\mathrm{Al}}=\ln \Omega,
$$



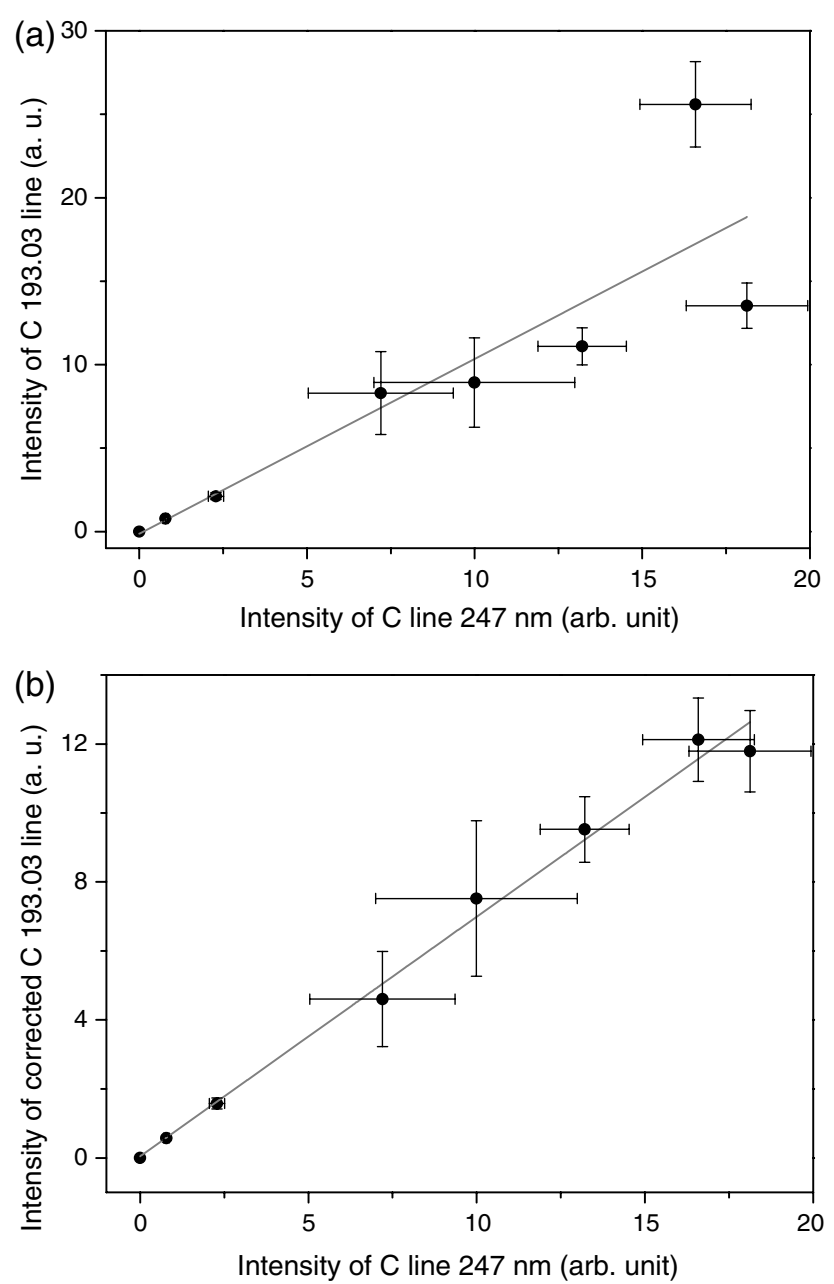

Fig. 4. LIBS intensities of the $\mathrm{C}$ line at $193.03 \mathrm{~nm}$ (a) without and (b) with the correction of interference of $\mathrm{Al}$ lines as a function of the $\mathrm{C}$ line at $247.86 \mathrm{~nm}$. The Pearson's correlation coefficients were (a) 0.86 and (b) 0.96 .

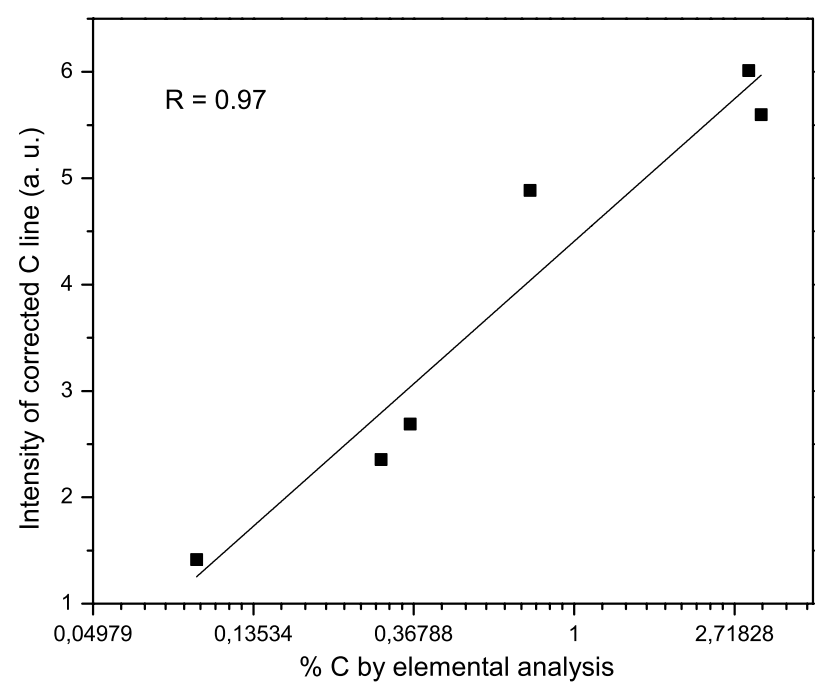

Fig. 5. LIBS intensities of the $\mathrm{C}$ line at $193.03 \mathrm{~nm}$ without the interference of $\mathrm{Al}$ lines as a function of the $\mathrm{C}$ concentration determined by elemental analysis for spodosol samples. The Pearson's correlation coefficient was 0.97 . where $\Omega$ corresponds to the $\mathrm{C}$ concentration measured by elemental analysis, and the " $\alpha_{2}$ " parameter was optimized by performing a linear fitting for the best Pearson's coefficient.

Figure 5 shows the LIBS intensities of the $\mathrm{C}$ line at $193.03 \mathrm{~nm}$ without the interference of $\mathrm{Al}$ lines as a function of the $\mathrm{C}$ concentration determined by elemental analysis for the spodosol samples. The value of the parameter $\alpha_{2}$ in Eq. (2) at the best fit was $1.20 \pm 0.05$. A strong correlation (Pearson's correlation coefficient for the linear fit $=0.97$ ) was found. The nonlinear curve at the $193.03 \mathrm{~nm}$ line represents a self-absorbed line $[26,28]$; thus a logarithmic scale was used to fit the curve.

Few points could be considered in Fig. 5 because of the small amount of spodosol samples. Thus, the oxisol samples were used for developing the calibration and validation model. Figure $\underline{6(a)}$ shows the LIBS

(a)
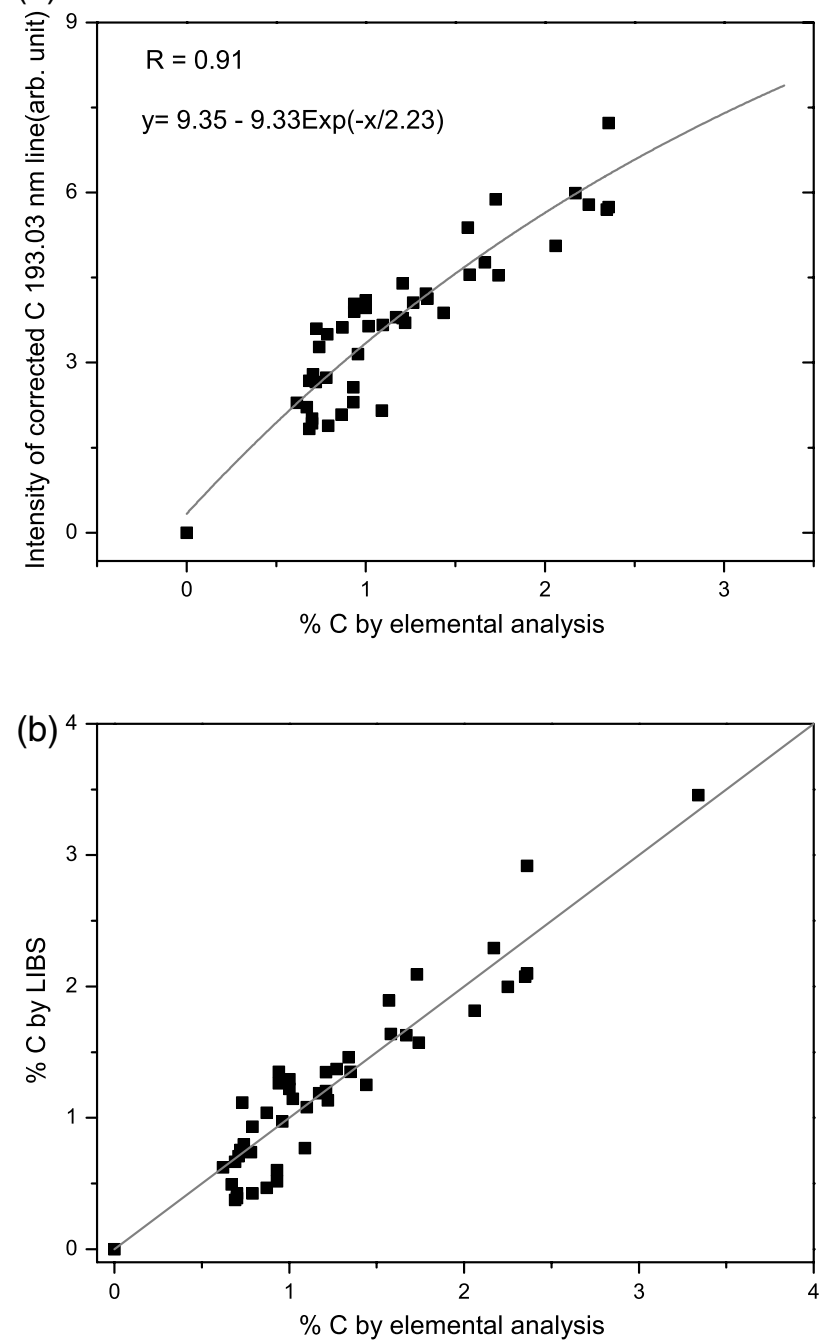

Fig. 6. LIBS intensities of the $\mathrm{C}$ line at $193.03 \mathrm{~nm}$ without the interference of $\mathrm{Al}$ lines as a function of the $\mathrm{C}$ concentration determined by elemental analysis for (a) oxisol samples and (b) validation data. The Pearson's correlation coefficient was (a) 0.91 for the calibration curve and (b) 0.91 for the validation. The LOD found was $0.28 \%$. 
intensities of the $\mathrm{C}$ line at $193.03 \mathrm{~nm}$ without the interference of $\mathrm{Al}$ lines as a function of the $\mathrm{C}$ concentration determined by elemental analysis for oxisol samples. Figure $\underline{6(b)}$ shows the validation data. The value of the parameter $\alpha_{2}$ in Eq. (2) at the best fit was $1.25 \pm 0.05$. A strong correlation (Pearson's coefficient for the exponential fit was higher than 0.91 ) was found. The best value for the optimization parameter was extracted, and cross validation was performed, obtaining a mean error of about $19 \%$ [Fig. 6(b)]. The same logarithmic model was applied to the reference data, obtaining a strong correlation coefficient using $\alpha_{2}$ as suggested in this calibration.

\section{Conclusion}

In this study the feasibility of a direct, portable, and relatively simple technique, such as LIBS, has been investigated to measure the concentration of $\mathrm{C}$ in forest soils, using the well-established elemental analysis analysis as the reference technique. Carbon has a few emission lines; the main $\mathrm{C}$ atomic lines are at 193.03 and $247.86 \mathrm{~nm}$ due to the strong interference of $\mathrm{Fe}, \mathrm{Si}$, and other lines. The line at $193.03 \mathrm{~nm}$ shows interference of $\mathrm{Al}$ lines; however, in this study we developed a method able to correct the $\mathrm{Al}$ interference on the C I (193.03 nm) LIBS emission line, and a strong correlation $(R>0.91)$ was found between the $\mathrm{C}$ content measured by LIBS and elemental analysis in a set of forest soils.

In conclusion, the results presented in this study show the promising potential of the LIBS technique for in situ quantitative analysis of $\mathrm{C}$ using a portable, low-resolution LIBS apparatus. Furthermore, the model developed here has the potential to correct other interfering emission lines. Although lines not interfered by other elements are preferentially used, this method represents a novel alternative for the exploration of other emission lines. Finally, applications to materials other than soils appear very promising.

The authors thank FAPESP, CNPq, CAPES (Brazilian research funding agencies), and EMBRAPA for their financial support of this study.

\section{References}

1. D. W. Reeves, "The role of soil organic matter in maintaining soil quality in continuous cropping systems," Soil Tillage Res. 43, 131-167 (1997)

2. C. C. Barford, S. C. Wofsy, M. L. Goulden, J. W. Munger, E. H. Pyle, S. P. Urbanski, L. Hutyra, S. R. Saleska, D. Fitzjarrald, and K. Moore, "Factors controlling long- and short-term sequestration of atmospheric $\mathrm{CO}_{2}$ in a mid-latitude forest," Science 294, 1688-1691 (2001).

3. Climate Change, The Scientific Basis, Intergovernmental Panel Climate Change, 2001, http://www.grida.no/climate/ ipcc_tar/wg1/index.htm.

4. M. J. Metzeger, M. D. A. Rounsevell, L. Acosta-Michlik, R. Leemans, and D. Schotere, "The vulnerability of ecosystem services to land use change," Agric. Ecosyst. Environ. 114, 69-85 (2006).

5. Y. Malhi, D. Wood, T. R. Baker, J. Wright, O. L. Philips, T. Cochrane, P. Meir, J. Chave, S. Almeida, L. Arroyo, N. Higuchi, T. J. Killeen, S. G. Laurance, W. F. Laurance, S. L. Lewis, A. Monteagudo, D. A. Neill, P. N. Vargas, N. C. A. Pitman, C. A.
Quesada, R. Salomão, J. N. M. Silva, A. T. Lezama, J. Terborgh, R. V. Martínez, and B. Vinceti, "The regional variation of aboveground live biomass in old-growth Amazonian forests," Glob. Chang. Biol. 12, 1107-1138 (2006).

6. Climate Change, The Physical Science Basis, Contribution of working group I to the fourth assessment report of the Intergovernmental Panel on Climate Change, WMO/UNEP, Paris (2007).

7. Y. Lucas, A. Chauvel, R. Boulet, G. Ranzani, and F. Scatolini, "Transição latossolos- podzois sobre a formação Barreiras na região de Manaus, Amazônia,” R. Bras. Ci. Solo 8, 325-335 (1984).

8. C. R. Montes, Y. Lucas, O. J. R. Pereira, R. Achard, M. Grimaldi, and A. J. Melfi, "Deep plant-derived carbon storage in Amazonian podzols," Biogeosciences 8, 113-120 (2011).

9. N. H. Batjes and J. A. Dijkshoorn, "Carbon and nitrogen stocks in the soils of the Amazon region," Geoderma 89, 273-286 (1999).

10. R. C. Izaurralde, C. W. Rice, L. Wielopolski, J. B. Reeves, A. M. Thomson, R. Harris, B. Francis, S. Mitra, A. G. Rappaport, J. D. Etchevers, K. D. Sayre, B. Govaerts, and G. W. McCarty, "Evaluation of three field-based methods for quantifying soil carbon," PLoS ONE 8, e55560 (2013).

11. D. M. B. P. Milori, A. Segnini, W. T. L. Da Silva, A. Posadas, V. Mares, R. Quiroz, and L. Martin-Neto, "Emerging techniques for soil carbon measurements," in CCAFS Working Paper 2 (2011), pp. 1-26.

12. R. J. Gehl and C. W. Rice, "Emerging technologies for in situ measurement of soil carbon," Clim. Change 80, 43-54 (2007).

13. D. Santos, Jr., L. V. G. Tarelho, F. J. Krug, D. M. B. P. Milori, L. Martin-Neto, and N. D. Vieira, Jr., "Espectrometria de emissão ótica com plasma induzido por laser (LIBS): fundamentos, aplicações e perspectivas," Revista Analytica 24, 72-81 (2006).

14. C. Pasquini, J. Cortez, L. M. C. Silva, and F. B. Gonzaga, "Laser induced breakdown spectroscopy," J. Br. Chem. Soc. 18, 463-512 (2007).

15. D. A. Cremers, M. H. Ebinger, D. D. Breshears, P. J. Unkefer, S. A. Kammerdiener, M. J. Ferris, K. M. Catlett, and J. R. Brown, "Measuring total soil carbon with laser-induced breakdown spectroscopy (LIBS)," J. Environ. Quality 30, 2202-2206 (2001).

16. M. H. Ebinger, M. L. Norfleet, D. D. Breshears, D. A. Cremers, M. J. Ferris, P. J. Unkefer, M. S. Lamb, K. L. Goddard, and C. W. Meyer, "Extending the applicability of laser-induced breakdown spectroscopy for total soil carbon measurement," Soil Sci. Soc. Am. J. 67, 1616-1619 (2003).

17. R. M. Da Silva, D. M. B. P. Milori, E. C. Ferreira, E. J. Ferreira, F. J. Krug, and L. Martin-Neto, "Total carbon measurement in whole tropical soil sample," Spectrochim. Acta, Part B 63, 1221-1224 (2008).

18. M. V. Belkov, V. S. Burakov, A. De Giacomo, V. V. Kiris, S. N. Raikov, and N. V. Tarasenko, "Comparison of two laserinduced breakdown spectroscopy techniques for total carbon measurement in soils," Spectrochim. Acta, Part B 64, 899-904 (2009).

19. A. M. Popov, F. Colao, and R. Fantoni, "Spatial confinement of laser-induced plasma to enhance LIBS sensitivity for trace elements determination in soils," J. Anal. At. Spectrom. 25, 837-848 (2010)

20. D. E. Lewis, J. Martinez, C. A. Akpovo, L. Johnson, A. Chauhan, and M. D. Edington, "Discrimination of bacteria from Jamaican bauxite soils using laser-induced breakdown spectroscopy," Anal. Bioanal. Chem. 401, 2225-2236 (2011).

21. S. C. Jantzi and J. R. Almirall, "Characterization and forensic analysis of soil samples using laser-induced breakdown spectroscopy (LIBS)," Anal. Bioanal. Chem. 400, 3341-3351 (2011).

22. E. C. Ferreira, D. M. B. P. Milori, E. J. Ferreira, L. M. Dos Santos, L. Martin-Neto, and A. R. de A. Nogueira, "Evaluation of laser induced breakdown spectroscopy for multielemental determination in soils under sewage sludge application," Talanta 85, 435-440 (2011). 
23. G. S. Senesi, M. Dell'Aglio, R. Gaudiuso, A. DeGiacomo, C. Zaccone, O. De Pascale, T. M. Miano, and M. Capitelli, "Heavy metal concentrations in soils as determined by laser-induced breakdown spectroscopy (LIBS), with special emphasis on chromium," Environ. Res. 109, 413-420 (2009).

24. M. Dell'Aglio, R. Gaudiuso, G. S. Senesi, A. DeGiacomo, C. Zaccone, T. M. Miano, and O. DePascale, "Monitoring of Cr, $\mathrm{Cu}, \mathrm{Pb}, \mathrm{V}$ and $\mathrm{Zn}$ in polluted soils by laser induced breakdown spectroscopy," J. Environ. Monit. 13, 1422-1426 (2011).

25. D. Diaz, D. W. Hahn, and A. Molinat, "Evaluation of laserinduced breakdown spectroscopy (LIBS) as a measurement technique for evaluation of total elemental concentration in soils,” Appl. Spectrosc. 66, 99-106 (2012).
26. K. K. Ayyalasomayajula, Y. Y. Fang, J. P. Singh, D. L. McIntyre, and J. Jain, "Application of laser-induced breakdown spectroscopy for total carbon quantification in soil samples," Appl. Opt. 51, B149-B154 (2012).

27. X. N. He, W. Hu, C. M. Li, L. B. Guo, and Y. F. Lu, "Generation of high-temperature and low-density plasmas for improved spectral resolutions in laser-induced breakdown spectroscopy," Opt. Express 19, 10997-11006 (2011).

28. R. Wisbrun, I. Schechter, R. Niessner, H. Schroeder, and K. L. Kompa, "Detector for trace elemental analysis of solid environmental-samples by laser plasma spectroscopy," Anal. Chem. 66, 2964-2975 (1994). 